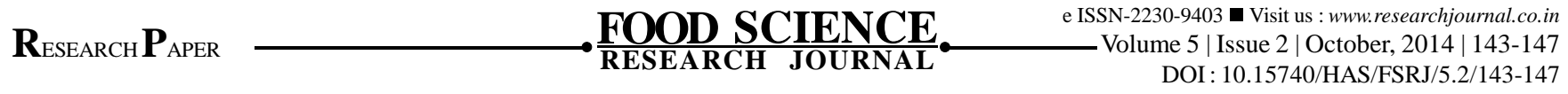

\title{
A study on effect of antioxidants on edible oil
}

\author{
Meena Mehta
}

\begin{abstract}
Vegetable edible oil is perishable ingredients in daily consumption of food. It deteriorates rapidly under Indian climatic conditions. Ever increasing and steady demand for consumption edible oil, it becomes necessary to investigate their shelf -life. Various causes are documented for the deterioration of oil. Hence, during processing and refining of oil, it is fortified with the various synthetically prepared antioxidants. The major antioxidants added in edible oil are t-Butyl Hydro Quinone (TBHQ), Butylated hydroxy anisole (BHA) and Propyl gallate (PG). A study was planned to investigate the effect of different degree of fortification of antioxidants on shelf -life of the oil. Each sample of oil was analyzed chemically and interpreted with respect to change in their shelf -life. It showed that out of these three antioxidants, BHA was most effective and PG was found to be least effective.
\end{abstract}

Key Words : Antioxidant, Edible oil, Shelf-life

How to cite this article : Mehta, Meena (2014). A study on effect of antioxidants on edible oil. Food Sci. Res. J., 5(2): 143-147.

MEENA MEHTA, Department of Food Science and Nutrition, Dr. B.M. Nanavati

College of Home Science, Matunga, MUMBAI (M.S.) INDIA

Email: bipin_281050@yahoo.com 